\title{
Antiquity of "Sail-Backed" Neural Spine Hyper-Elongation in Mammal Forerunners
}

\author{
Arjan Mann ${ }^{1}$ and Robert R. Reisz ${ }^{2 *}$ \\ 'Department of Earth Sciences, Carleton University, Ottawa, ON, Canada, ${ }^{2}$ Department of Biology, University of Toronto \\ Mississauga, Mississauga, ON, Canada
}

Neural spine hyper-elongation in tetrapods is a unique morphological adaptation that creates a dorsal sail. While this extreme morphology has appeared several times in the evolutionary history of tetrapods, it was first experimented with by the nonmammalian synapsid paraphyletic group known as "Pelycosaurs," famously represented by the Permian apex predator Dimetrodon. Here we provide new fossil data tracing the evolution of this morphological innovation back to the initial Carboniferous radiation of the synapsid clade. We describe a new hyper-elongated neural spine belonging to the earliest ophiacodontid synapsid Echinerpeton intermedium, from the Pennsylvanianaged deposits of Florence, Nova Scotia. The new fossil unveils the rapid convergence

OPEN ACCESS

Edited by:

Michel Laurin,

UMR7207 Centre de Recherche sur la Paléobiodiversité et les Paléoenvironnements (CR2P), France

Reviewed by:

Neil Brocklehurst, University of Oxford, United Kingdom Kenneth Angielczyk Field Museum of Natural History, United States

*Correspondence:

Robert R. Reisz robert.reisz@utoronto.ca

Specialty section: This article was submitted to Paleontology, a section of the journal Frontiers in Earth Science

Received: 20 November 2019 Accepted: 10 March 2020 Published: 03 April 2020

Citation: Mann A and Reisz RR (2020) Antiquity of "Sail-Backed" Neural Spine Hyper-Elongation in Mammal Forerunners. Front. Earth Sci. 8:83. doi: 10.3389/feart.2020.00083 and repeated evolution of the "dorsal sail" morphology in Synapsida. The development of this trait may have given early synapsids a unique advantage in their early radiation over the other early amniotes, the reptiles.

Keywords: sail-backed, Synapsida, Carboniferous, vertebral evolution, neural spine hyper-elongation

\section{INTRODUCTION}

Vertebral neural spine hyper-elongation (NSH) is a rare phenomenon in tetrapod backbones that gives the appearance of a dorsally protruding "sail" or "fin" on the animal. These bony "sails" protrude from the bulk of the trunk, including muscle and adipose tissue, and may be covered by a thin epithelium and collagenous integumentary webbing. Only a few extant squamates have true "sail-backs," including the agamid genus Hydrosaurus, the chameleonid genus Trioceros as well as the corytophanid genus Basiliscus and its species (Bramwell and Fellgett, 1973). These sails are variable in where they appear on the body and are covered by a thin integumentary webbing. Long vertebral neural spines are also present in mammals such as the American Bison (Bison bison), however, these are often covered by a soft tissue combination of epaxial musculature and adipose tissue, which creates the appearance of a "hump-back" (Bailey, 1997). While in living tetrapods NSH is limited to reptiles, examination of the fossil record of amniotes reveals that this morphology has appeared several times in the evolutionary history of tetrapods.

Among fossil amniotes, NSH is observed in various iconic archosaur lineages, including both carnivorous and herbivorous dinosaurs such as Spinosaurus and Ouranosaurus, respectively (Hone and Holtz, 2017). It is also present in other groups such as the poposaurid Arizonasaurus (Nesbitt, 2003). However, neural spine hyper-elongation is probably most iconic in the early mammal forerunner Dimetrodon. The earliest amniotes to experiment with such morphology are the "pelycosaurian-grade" synapsids, like the Early Permian apex-predator Dimetrodon and the tall-spined early high-fiber herbivore Edaphosaurus (Huttenlocker et al., 2010, 2011). Here we provide the earliest empirical 
evidence of NSH in tetrapods, particularly from new material of the early ophiacodontid synapsid Echinerpeton intermedium (Reisz, 1972; Mann and Paterson, 2019). Together, Echinerpeton and its contemporary ophiacodontid Archeothyris florensis, are the earliest definitive representations of the synapsid lineage (Mann and Paterson, 2019). Our new anatomical evidence reveals that the antiquity of NSH is closely linked to the initial radiation of synapsids during the Late Carboniferous. The presence of this trait in an ophiacodontid indicates a wider distribution of NSH in pelycosaurian synapsids than previously known, with the trait evolving convergently at least three times. Finally, although the function of NSH in fossil amniotes remains enigmatic, we are able to comment on current hypotheses, such as thermoregulatory function and intra-species recognition, based on the amniote dominated fossil fauna of Florence, Nova Scotia.

\section{MATERIALS AND METHODS}

Specimens were studied at the Redpath Museum (RM), Montreal; the Canadian Museum of Nature, Ottawa; the Field Museum of Natural History, Chicago; the Yale Peabody Museum, New Haven; and the Harvard Museum of Comparative Zoology (MCZ), Cambridge.

In order to confirm the proposed taxonomic identity of ROM VP 83326, the specimen was compared directly to RM 10057, a paratype of Echinerpeton intermedium, alongside several members of basal synapsid groups, including well-known members of Ophiacodontidae. ROM VP 83326 was compared to casts and photographs of the holotype series of Echinerpeton and Archaeothyris, as well as other synapsid remains from Florence, NS, Canada.

Measurements were taken using manual calipers, and photographs were taken using a Sony Alpha ILCE 5000 camera with an F3.5 lens. All figures were drawn and formatted in Photoshop CS6 (Adobe, San Jose, CA, United States).

\section{SYSTEMATIC PALEONTOLOGY \\ Amniota (Haeckel, 1866) Synapsida (Osborn) \\ Ophiacodontidae (Nopcsa, 1923) \\ Echinerpeton intermedium (Reisz, 1972) \\ Referred material- ROM VP 83326 (Figure 1)}

\section{Locality and Horizon}

Sydney Mines Formation ( 308.5-305.5 Ma), Morien Group, less than 25 feet above the Lloyd Cove coal seam, equivalent to the late Westphalian D of Europe (Allen et al., 2014). Dominion Coal Co., strip mine No. 7, 2 miles north of Florence, Cape Breton County, Nova Scotia. Collected during the 1950's or 1960's by a PrincetonMcGill field party.

\section{Comparative Anatomy}

Prior to this study the vertebral column of Echinerpeton intermedium was relatively well known from the holotype and referred material (Reisz, 1972; Mann and Paterson, 2019).
While the vertebrae have always been distinguished from Archeothyris based on their long, slender neural arches, whether or not they were truly hyper-elongate has been obscured by the juvenile condition of the known specimens. Aside from neural spine length ROM VP 83326 is morphologically indistinguishable from the neural arches on the holotype (Figure 1). The neural spine height is at least $7 \mathrm{~cm}$ tall, is $2.3 \mathrm{~mm}$ in width, increasing slightly in width distally before tapering again toward its distalmost tip. Overall, the morphology remains extremely thin, as in the type series (Reisz, 1972; Mann and Paterson, 2019). There is no centrum preserved. This likely indicates that the neural arches are not fused to the centrum, suggesting that these remains likely belonged to an immature individual, but ontogenetically more advanced than the smaller holotype material of Echinerpeton (Reisz, 1972; Mann and Paterson, 2019). We estimate the neural spine to centrum ratio to be 13 times the height of the corresponding centrum, Romer and Price (1940) found that hyper-elongate spines in sphenacodontids were 18-25 times the height of the corresponding centrum. The base of the neural spine is covered by a relatively large, subtriangular skull element, the left parietal preserved in dorsal aspect. This element is lightly ornamented with pitting and small radiating ridges. A prominent excavation for the parietal foramen is visible medially. The parietal bears a prominent anterior process, and a small posterolateral process.

Despite the overlapping parietal on the base of the neural spine, most of the neural arch is preserved. The prezygapophysis is a small pinch out from the main body at the ventralmost portion of the preserved neural spine. A small poorly preserved transverse process is represented by laterally raised edges of bone on the neural spine base. Posteriorly, a well-preserved postzygapophysis is present, and is developed as a gradual pinching out of the main body. Overall these processes resemble the gracile, weakly developed morphology present in the holotype of Echinerpeton, but also ophiacodontids in general (Reisz, 1972; Mann and Paterson, 2019).

Approximately $2 \mathrm{~cm}$ distally from the smooth surfaced base of the neural spine, there is a "changing point" where longitudinal grooves appear, these are analogous with the vascular grooves found on the neural spines of other pelycosaurian synapsids. Huttenlocker et al. (2010) provided histological data through this "changing point" in sphenacodontids, showing that the proximal neural spine base bears numerous Sharpey's fibers acting as the sites of attachment for epaxial musculature, while distally, Sharpey's fibers are replaced with numerous vascular grooves. Thus, this distal region would protrude beyond the main body creating a dorsal sail, as shown in other early synapsid hyper-elongated neural spines (Huttenlocker et al., 2010, Figures 6-10). The vascular grooves on ROM VP 83326 appear to occupy at least two-thirds the entire length of the neural spine, thus indicating the majority of the neural spine protruded dorsally and should be considered hyper-elongated in morphology. 


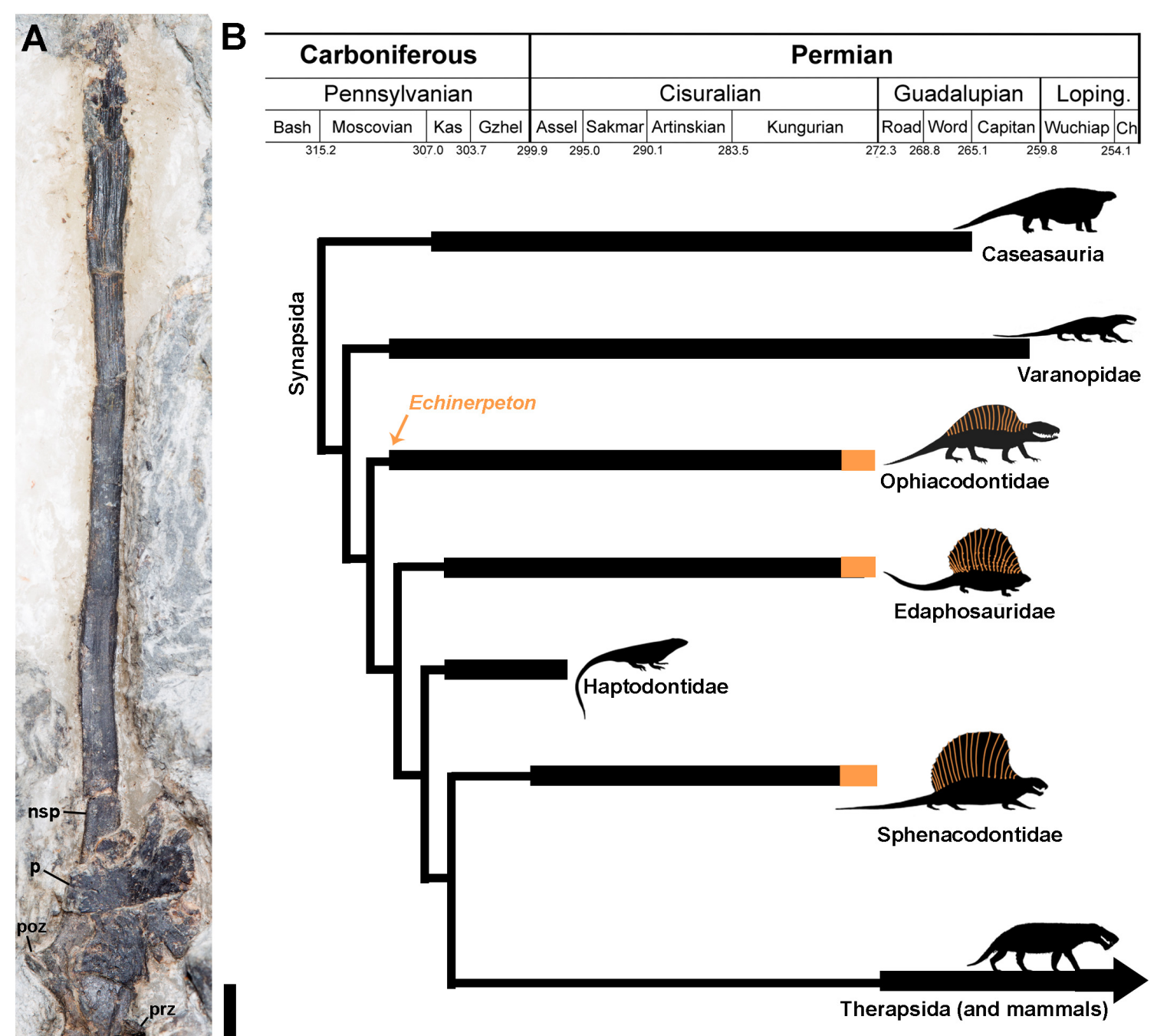

$1 \mathrm{~cm}$

FIGURE 1 | (A) Hyper-elongated neural spine of Echinerpeton intermedium (B) Simplified time-calibrated cladogram (based on the relationships of Benson, 2012 and divergence dates of Maddin et al., 2020) showing the evolution of neural spine hyper-elongation in basal Synapsida indicated in orange. The orange arrow indicates the age of Echinerpeton intermedium. Anatomical abbreviations: nsp, neural spine; p, parietal; trpr, transverse process; poz, postzygapophysis; prz, prezygapophysis.

It should be noted, there is slight undulation along the neural spine but not to the degree observed in species of Dimetrodon, or Edaphosaurus. There are no protuberances or bony growths on the neural spine, nor is the spine round or dumbbell shaped cross-section, but instead appears laterally compressed and likely has a ovular cross-section that thins toward the distalmost end (although this is only based on the lateral aspect). The combination of these features may be autapomorphic to Echinerpeton.

\section{DISCUSSION}

Our new material belonging to the ophiacodontid Echinerpeton intermedium provides the oldest known instance of neural spine hyper-elongation in the fossil record of tetrapods (Figure 1). Fossils of Echinerpeton are currently only known from the Carboniferous-aged erect Sigillaria tree stump fauna of Sydney Mines Formation, Florence, NS, Canada (Reisz, 1972; Mann and Paterson, 2019). This horizon provides the earliest record of a diverse amniote fauna that is 
dominated by synapsids (Reisz, 1972; Spindler, 2014; Mann and Paterson, 2019; Maddin et al., 2020) and with only a single basal eureptile (Carroll, 1969). Current chronostratigraphic calibrations of reptilian and synapsid phylogenetic trees also reveal that synapsids were more diverse in this early stage of amniote evolution, with the late Carboniferous synapsid diversity outpacing that of early reptiles (Modesto et al., 2015; Didier and Laurin, 2020). Superficially, early amniotes possess similar bauplans and share a number of craniodental traits, thus morphological adaptations responsible for the Carboniferous ecological success of Synapsida is difficult to assess.

However, at least one morphological adaptation, NSH is an unusual phenomenon restricted to early Synapsida in Paleozoic amniotes, and appears to already be present in the earliest fossil representatives of the clade. It is possible that experimentation with this morphological trait, in part, led to the early success of the clade. Furthermore, this trait appears to have been only present amongst the basal pelycosaurian synapsids, with no other stem or living mammal group ever re-evolving a true dorsal sail, and no reptiles evolving this morphology until the Mesozoic era.

Among early synapsids NSH appears to have convergently evolved at least three times, once within Ophiacodontidae (evidenced here by Echinerpeton intermedium), and independently within Edaphosauridae (Huttenlocker et al., 2011; Spindler et al., 2019), and Sphenacodontidae (Figure 1). Within Sphenacodontidae a single appearance of neural spine hyperelongation is plausible with a subsequent diversification in shape, however, the evolution of this trait may be even more complex, with the trait potentially evolving at least twice, and possibly thrice independently within the clade. For example, the hyper-elongated neural spines of the sphenacodontids Ctenospondylus and Sphenacodon appear to retain the primitive bladed distal configuration, while the spines of Secodontosaurus and Dimetrodon are not only longer, but also subcircular in cross section and tapering distally. A third possible evolution of this

\section{REFERENCES}

Allen, J. P., Fielding, C. R., Gibling, M. R., and Rygel, M. C. (2014). Recognizing products of palaeoclimate fluctuation in the fluvial stratigraphic record: an example from the Pennsylvanian to Lower Permian of Cape Breton Island. Nova Scotia. Sedimentology. 61, 1332-1138.

Bailey, J. B. (1997). Neural spine elongation in dinosaurs: sailbacks or buffalobacks? J. Paleontol. 71, 1124-1146. doi: 10.1017/s0022336000036076

Benson, R. B. J. (2012). Interrelationships of basal synapsids: cranial and postcranial morphological partitions suggest different topologies. J. Syst. Palaeonto. 10, 601-624. doi: 10.1080/14772019.2011.631042

Bramwell, C. D., and Fellgett, P. B. (1973). Thermal regulation in sail lizards. Nature 242:203. doi: $10.1038 / 242203 \mathrm{a} 0$

Brocklehurst, N., and Brink, K. S. (2017). Selection towards larger body size in both herbivorous and carnivorous synapsids during the Carboniferous. Facets 2, 68-84. doi: 10.1139/facets-2016-0046

Carroll, R. L. (1969). A middle pennsylvanian captorhinomorph and the interrelationships of primitive reptiles. J. Paleontol. 43, 151-170.

Didier, G., and Laurin, M. (2020). Exact distribution of divergence times from fossil ages and tree topologies. bioRxiv [preprint]. doi: 10.1101/490003

Haeckel, E. (1866). Generelle Morphologie der Organismen. Allgemeine Grundzüge der organischen Formen-Wissenschaft, mechanisch begrüundet durch die von $C$. Darwin reformirte Descendenz-Theorie. Vol 2. Berlin: Reimer, 574. trait is present in Ctenorhachis (Hook and Hotton, 1991) that resembles Sphenacodon but has slightly longer neural spines that distally taper to a thin blade.

Currently it is unclear whether hyper-elongate neural spines in basal synapsids served a thermoregulatory function (though apparently not supported by histological data see Huttenlocker et al., 2010, 2011), served in intra-species recognition (i.e., the recognition by a member of a species of a conspecific, including mate recognition for reproduction) (Huttenlocker et al., 2011), or a combination of the two. However, taking into account the lack of correlation between patterns of body size evolution and dorsal "sail" evolution, as well as the disparity of neural spine shape and ornamentation, support for hyperelongate neural spines as secondary sexual characters in early synapsids seems likely (Tomkins et al., 2010; Brocklehurst and Brink, 2017). The repeated selection toward the evolution of a "sail-backed" hyper-elongated neural spine morphology in multiple early synapsid groups suggests that there was something biologically unique in early synapsids distinguishing them from their reptilian contemporaries, perhaps a metabolic difference in early synapsids, noted to be the earliest large terrestrial amniotes in the fossil record.

\section{DATA AVAILABILITY STATEMENT}

The original contributions presented in the study are included in the article/supplementary materials, further inquiries can be directed to the corresponding author.

\section{AUTHOR CONTRIBUTIONS}

AM and RR contributed equally to the study design and writing of the manuscript. AM made the figure.

Hone, D. W., and Holtz, T. R. (2017). A century of spinosaurs-a review and revision of the Spinosauridae with comments on their ecology. Acta Geol. Sin. 91, 1120-1132. doi: 10.1111/1755-6724.13328

Hook, R. W., and Hotton, N. III (1991). A new sphenacodontid pelycosaur (Synapsida) from the Wichita Group. Lower Permian of north-central Texas. J. Vertebrate Paleontol. 11, 37-44. doi: 10.1080/02724634.1991.10011374

Huttenlocker, A. K., Mazierski, D., and Reisz, R. R. (2011). Comparative osteohistology of hyperelongate neural spines in the Edaphosauridae (Amniota: Synapsida). Palaeontology 54, 573-590.

Huttenlocker, A. K., Rega, E., and Sumida, S. S. (2010). Comparative anatomy and osteohistology of hyperelongate neural spines in the sphenacodontids Sphenacodon and Dimetrodon (Amniota: Synapsida). J. Morphol. 271, 14071421. doi: 10.1002/jmor.10876

Maddin, H. C., Mann, A., and Hebert, B. (2020). Varanopid from the carboniferous of nova scotia reveals evidence of parental care in amniotes. Nat. Ecol. Evol. 4, 50-56. doi: 10.1038/s41559-019-1030-z

Mann, A., and Paterson, R. S. (2019). Cranial osteology and systematics of the enigmatic early 'sail-backed'synapsid Echinerpeton intermedium Reisz, 1972, and a review of the earliest 'pelycosaurs'. J. Syst. Palaeontol. 18, 529-539. doi: $10.1080 / 14772019.2019 .1648323$

Modesto, S. P., Scott, D. M., MacDougall, M. J., Sues, H. D., Evans, D. C., and Reisz, R. R. (2015). The oldest parareptile and the early diversification of reptiles. Proc. R. Soc.BBiol. Sci. 282, 2014-1912. doi: 10.1098/rspb.2014.1912 
Nesbitt, S. J. (2003). Arizonasaurus and its implications for archosaur divergence. Proc. R. Soc. Lon. Seri. B Biol. Sci. 270, S234-S237.

Nopcsa, F. (1923). Die Familien der Reptilien. Fortschritte der Geologie und Palaontologie. Berlin: Gebrüder Borntraeger, 1-210.

Reisz, R. (1972). Pelycosaurian Reptiles From the Middle Pennsylvanian of North America. Harvard: Harvard University.

Romer, A. S., and Price, L. I. (1940). Review of the Pelycosauria, Vol. 28. Boulder, CO: Geological Society of America.

Spindler, F. (2014). Reviewing the question of the oldest therapsid. Paläontol. Stratigraphie Fazies 22, 1-7.

Spindler, F., Voigt, S., and Fischer, J. (2019). Edaphosauridae (Synapsida, Eupelycosauria) from Europe and their relationship to North American representatives. PalZ 1-29.

Tomkins, J. L., LeBas, N. R., Witton, M. P., Martill, D. M., and Humphries, S. (2010). Positive allometry and the prehistory of sexual selection. Am. Nat. 176, 141-148. doi: $10.1086 / 653001$
Conflict of Interest: RR is a section editor for Frontiers.

The remaining author declares that the research was conducted in the absence of any commercial or financial relationships that could be construed as a potential conflict of interest.

The reviewer NB declared a past co-authorship with one of the authors RR to the handling Editor.

Copyright (c) 2020 Mann and Reisz. This is an open-access article distributed under the terms of the Creative Commons Attribution License (CC BY). The use, distribution or reproduction in other forums is permitted, provided the original author(s) and the copyright owner(s) are credited and that the original publication in this journal is cited, in accordance with accepted academic practice. No use, distribution or reproduction is permitted which does not comply with these terms. 